to the group to which attention has been drawn by Professor Osler. He distinguishes the condition from hæmophilia and in reference to this it will be noted that in the present instances, as indeed in Professor Osler's own cases, victims are supplied from both sexes. Again, the woman whose condition is described above denied that spontaneous hæmorrhage, either in herself or the members of her family, ever occurred from any part other than the nose and she did not consider that there was any family disposition to bleed in excess from any slight injury. One of her finger tips, as above described, had often bled but never to an extent to canse more than temporary inconvenience.

The present record may be noted as illustrating the hereditary tendency of the condition, its incidence in both sexes, and its wide distribution over the members of the family affected.

Harley-street, W.

\section{AN UNUSUAL CASE OF FEMORAL HERNIA.}

By J. Sidney Pearson, M.A., M.B. Cantab., RESIDENT MEDICAL OFFICER AT ST. MARY'S HOSPITAL, PLAISTOW, E,

A BoY, aged three years, was admitted on Dec. 12th, 1905, into St. Mary's Hospital, Plaistow, for right inguinal hernia. The hernia had not been seen down nor would the usual means make it evident. However, as the mother's history was so positive and the right external ring was so large it was decided to perform a radical cure. Mr. A. E. Kennedy performed the operation but in spite of the most careful search no sac was discovered. Before sewing up the incision however, Mr. Kennedy suggested that the anæsthetic should be discontinued and when the boy began to vomit a hernia as large as a pigeon's egg at once became evident in the femoral canal. Accordingly, a vertical incision was made downwards over this and a typical femoral hernia was isolated. The sac was ligatured and cut off and then the pectineus was sutured to Poupart's ligament and the wound was closed. The boy made an uninterrupted recovery.

The extreme rarity of this condition in male infants justifies, I think, this brief record. Undoubtedly the hernia was congenital. Both testes were, however, in the scrotum, which is not usual in this condition, where the hernia follows generally the misplaced testis. According to the mother the testes had always been normally situated.

I am indebted to $\mathrm{Mr}$. Kennedy for his kind permission to publish this note.

Plaistow, E.

\section{g attirtor}

$$
\text { OF }
$$

\section{HOSPITAL PRACTICE, BRITISH AND FOREIGN.}

Nulla autem est alia pro certo noscendi via, nisi quamplurimas et morborum et dissectionum historias, tum aliorum tum proprias Morb., lib. iv., Procmium.

\section{ST. MARY'S HOSPITAL.}

A CASE OF CALCULOUS AYURIA.

(Under the care of Mr. W. H. ClaYTON-GREENE.)

For the notes of the case we are indebted to Lieutenant R. Kuper White, I.M.S.

The history of the case is briefly as follows. On Sept. 18th, 1905 , the patient, a fat man, weighing 17 stones, and aged 56 years, was seized with renal colic. The attack was in every way typical; the pain was on the right side but gradually passed from the region of the kidney to the lower part of the abdomen. There was frequency of micturition and the urine at this time was loaded with blood. As far as could be ascertained there had been no typical attack previous to this one but four months before the patient had been attended for left-sided pain which was attributed to overloading of the sigmoid flexure and which entirely subsided after the exhibition of purgatives. There were no urinary symptoms. In the light of recent events it is probable that this attack of pain was produced by a stone becoming blocked in the left ureter. Mr.J. M. Barlet of Shaftesbury-avenue saw the man on the 18th and treated him for his colic but in the evening found that very little urine was being passed. He therefore ordered free purgation and gave diuretics and tincture of belladonna in the hope that the stone would be dislodged by the contractions of the ureter. No result followed. On the 2Znd a catheter was passed for the first time but the bladder was found as empty as it was supposed to be. This fact is mentioned because on examining the scrotum a wellmarked epididymitis was found which could not be explained as being due to the passage of instruments. On the evening of the 2 ind the patient's general condition was satisfactory, the pulse was quiet (76), the temperature was $99^{\circ} \mathrm{F}$, and there was little pain; the epididymitis on the right side was well marked. The renal regions were examined but nothing abnormal could be detected beyond rigidity of the right side of the abdomen. A catheter was passed into the bladder which was found empty and a rectal examination showed only a palpable prostate. It was clear, therefore, at this stage that a case of anuria had to be dealt with, the cause being in all probability a stone impacted in the ureter some little distance from the kidney. The 22nd was, moreover, the fourth day of the anuria, and as all previous treatment had been unsuccessful in moving the stone the other alternative-operation -had to be considered. The patient was naturally very averse to anything of the sort because, as be said, he felt perfectly well and he did not realise the gravity of the situation. As no preparation had been made for operating it was agreed to postpone matters till the morrow in order to try again the effects of belladonna combined with cupping over the loins.

On the following morning (Sept. 23rd), the fifth day of the anuria, as no progress had been made, the patient was taken to the theatre and under anæsthesia an examination of the bladder was made with the cystoscope. The right ureter appeared normal but the left was distended and some whitish material, which at the time it was thought might be a phosphatic stone, could be seen in the opening. It was clear, therefore, that the stone impacted on the right side was not in the region of the ureteric opening into the bladder. He was turned on to his side, after the loins had been palpated without result, and a long incision was made from the last rib well beyond the anterior superior spine. There was a good deal more bleeding than is usual in a renal case but this was attributed to the cupping. The kidney was first examined but no stone could be felt. The renal pelvis was quite free. The ureter was next picked up at the bottom of a wound several inches in depth and on tracing it down towards the pelvis a stone was felt some four or five inches from the lower pole of the kidney just above the iliac vessels. It was quite small and of about the size of a pea. The wound was well retracted and with considerable difficulty, and after the separation of surrounding structures the ureter was brought as near the surface as possible, though still lying at a depth of some six inches, and the stone was removed through a longitudinal incision. The stone was soft and broke during its removal but the walls of the ureter gripped it very tightly and it was not possible to move it either up or down. As soon as the stone had been extracted blood-stained urine welled up into the wound and the kidney was shown to be still active. A long catheter was passed down the ureter into the bladder from the incision through which the stone had been removed. There was no further obstruction. The edges of the opening in the ureter were approximated by three catgut sutures. It was thought better not to make any effort to effect a complete closure, as such treatment tends to narrow the tube, and if the duct gets blocked with clot, as often occurs, then there is further trouble until the tension is relieved. A large tube was fixed close to this ureteric opening and the lumbar wound was closed in the ordinary manner, a second tube being inserted at the posterior angle.

The progress of the case was from the first satisfactory. There were little shock after the operation and no great amount of pain. Urine flowed freely from the lumbar tubes but none was passed per urethram. A catheter withdrew some blood-stained fluid which was found to contain urea. After an initial rise the temperature fell to normal and urine was freely discharged through the wound, but on Sept. 28th the temperature again rose and continued to do so until Oct. 1st, the day on which the patient first passed urine in the natural manner. This was followed by a sudden fall 